\title{
Can Conventional Risk Factors Explain Excess Coronary Artery Disease Risk in South Asians: Dyslipidemias and Dysfunctional High Density Lipoprotein (HDL)
}

\author{
Sunita Dodani* \\ Center for Outcome Research and Education (CORE), Department of Internal Medicine, School of Medicine, \\ Kansas University Medical Center, Wescoe Room \# 4008, 3901 Rainbow Blvd., MS 1022, Kansas City, KS 66160, USA
}

\begin{abstract}
Over the past several years, the overall prevalence and incidence of cardiovascular diseases in general and coronary artery diseases (CAD) in particular have declined in the United States (US). However, among South Asian in general and South Asian immigrants in particular, a disturbing trend toward high rates of CAD has been noted. This trend is associated with a high prevalence of conventional risk factors and metabolic syndrome in this population, yet these conventional risk factors may not account for the greater CAD risk among SAIs. A search for additional markers is warranted, to enable early detection and prevention of CAD in this high risk group. High density lipoprotein (HDL) is one of the predictor of CAD and is considered to be cardio-protective. However, some of the recent studies have shown that HDL is not only ineffective as an antioxidant but, paradoxically, appears to be pro-oxidant, and has been found to be associated with CAD. Such HDL is called dysfunctional HDL. More research is required in South Asians to explore associations with $\mathrm{CAD}$ and to enhance early detection and prevention of CAD in this high risk group. We present here an overview on risk factors of CAD in general and dyslipidemias in particular in South Asians. In addition, concepts on dysfunctional HDL and its impact on CAD are also presented. At the end, recommendations are made to improve and prevent CAD morbidity and mortality in the South Asian communities.
\end{abstract}

\section{INTRODUCTION}

Among cardiovascular diseases, coronary artery disease (CAD) is the leading cause of death in the United States (US), and certain populations, such as South Asians, African Americans, and Hispanics, carry a disproportionately larger burden of CAD [1-3]. Even though CAD event rates have decreased by $50 \%$ in the US and other developed countries over the past 30 years, rates have doubled in South Asianspeople with ancestors from the Indian subcontinent (i.e. India, Pakistan, Bangladesh and others), and have risen even more among South Asians who immigrate to the US [2]. The mortality rates from CAD in South Asians are reported to be two to three times higher than those for Caucasians, irrespective of gender, religion, social class, dietary practices or country of residence $[3,4]$. This higher prevalence is seen in South Asians living in the United States, as well as, in those living in India, and rates are similar among vegetarians and non-vegetarians [3-8]. South Asian Indian women in California have the highest death rate from CAD in the United States, higher than Caucasians, Blacks, Hispanics, and Native Americans [9]. Specifically, 33\% of all deaths among Indian women are due to CAD compared with $11 \%$ among Japanese, $16 \%$ among Chinese, and $20 \%$ among Hispanics, Blacks, and Caucasians [9]. In California, South Asian immigrants have the highest rate of hospitalization for CAD, and Chinese have the lowest rate. Intermediate rates have been reported for Caucasians, Japanese, and Filipinos [9].

*Address correspondence to this author at the Department of Internal Medicine, School of Medicine, Kansas University Medical Center, Wescoe Room \# 4008, 3901 Rainbow Blvd., MS 1022, Kansas City, KS 66160, USA; Tel: 913-588-4765; Fax: 913.588.3995; E-mail: sdodani@kumc.edu
The high rates of CAD among South Asian immigrants are not limited to the United States and appear to be part of a global phenomenon [10]. Further, CAD risk factors are present in South Asians at a younger age compared to other populations, resulting in CAD at a younger age than in other populations [3]. The reasons for early development of CAD risk factors at a relatively young age in South Asian immigrants are still unclear.

More than 3.6 million South Asians live in the United States, and although this group represents the second fastest growing Asian immigrant population, little is known regarding their increased risk for CAD [2]. There has been much speculation about what causes the increased occurrence of and mortality from CAD in South Asian immigrants. Differences in CAD and stroke mortality between South Asians in other countries and those in South Asian countries could be due to either the effect of a new environment triggering latent susceptibilities that weren't triggered in the home country, or merely an effect of environmental and behavioral changes due to immigration on the incidence of these diseases. Not uniform groups, South Asians include ethnic subgroups with different cultures and practices, and the prevalence of recognized risk factors for CAD varies among the subgroups [8, 10-12]. As a whole, however, South Asians and South Asian immigrants have a much higher prevalence of diabetes, insulin resistance, central obesity, dyslipidemias (increased lipoprotein [a], higher triglycerides), increased thrombotic tendency (increased plasminogen activator inhibitor-1 and decreased tissue plasminogen activator levels), decreased levels of physical activity, and lower birth weights, commonly known as "fetal origins hypothesis syndrome" [3, 8, 11-17]. 


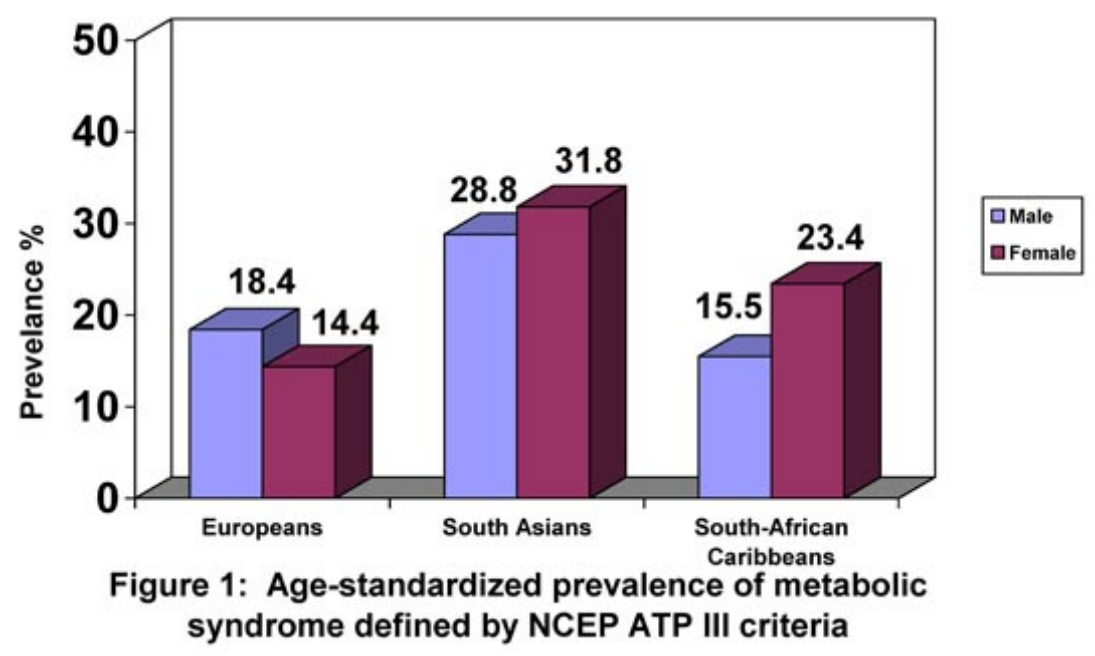

Fig. (1). Age-standardized prevalence of metabolic syndrome defined by NCEP ATP III criteria.

The higher CAD risk in South Asians may be related to a higher prevalence of metabolic syndrome which has become increasingly common among South Asian immigrants [16, $18,19]$ as compared to other populations (Fig. 1). However, even taking these differences into account, classical risk factors may not fully explain the increased risk for CAD in South Asians [3, 17-19]. Furthermore, conventional risk factors, insulin resistance parameters, metabolic syndrome may not account for the increased risk in South Asian immigrants $[9,17-20]$.

The CAD rates in the US, Australia, Canada, France, Japan, and Finland [14] have declined to half over the past 30 years (Fig. 1). These vast reductions in CAD mortality are generally attributed to nationwide changes in specific risk factors that were identified through epidemiological research and addressed through population-based interventions [2123]. Reduction in risk factors explains most of the decline with modest contributions from advances in treatment [2428]. Ironically, during this time, the CAD rates doubled in South Asian immigrants, and the impact of risk factors and genetic susceptibility appears to be greater in this population compared to others, making South Asian immigrants a high risk group [29]. Migration is an important factor in determining the increased risk of CAD; however, other migrating populations (e.g. Afro-Caribbean) do not have an increased risk of CAD compared with the indigenous population [13]. Thus, other specific factors must apply to this high risk population.

\section{DYSLIPIDEMIAS IN SOUTH ASIANS}

Among numerous genetic and lifestyle parameters, dyslipidemias are one of the most prominent risk factors for CAD. Epidemiological studies have identified low-density lipoprotein (LDL) and high-density lipoprotein (HDL) as independent risk factors that modulate CAD risk [30, 31]. Though the primary goal is to reduce LDL levels, however HDL cholesterol levels are among the most predictive risk factors for CAD [30, 31]. A growing body of experimental evidence suggests that augmenting the levels or function of HDL and its apolipoproteins can have major vascular protective effects ranging from prevention to stabilization and regression, independent of total or non-HDL cholesterol levels
[24-28]. The National Cholesterol Educational Program Adult Treatment Panel III (NCEP ATP III) guidelines clearly define an HDL level of $<40 \mathrm{mg} / \mathrm{dl}$ as an independent risk factor for CAD, and low HDL is often present in high-risk patients with CAD [30-32]. Although an inverse relationship between HDL and risk of acute myocardial infarction is highly significant, the relationship is far from perfect.

South Asian, in general tend to have higher triglycerides, lower HDL, and higher Lipoprotein a (Lpa) levels [33]. However, few recent studies on South Asian immigrants in the US showed that the average HDL level in both men and women was either normal or high $[34,35]$. Whether this difference in HDL level is due to differences in migration, physical activity, gene-environment interactions, or other unknown factors is not known.

Based on known ethnic differences in risk prediction, the Framingham prediction model accurately predicts the CAD risk among Caucasians and blacks living in the United States. For Americans of Japanese and Hispanic descent and for Native Americans, the Framingham model overestimates CAD risk. For South Asian immigrants, the Framingham model may underestimate CAD risk by greater than $100 \%$ [36-38]. Total cholesterol and LDL levels are correlated with the extent and severity of CAD in South Asian immigrants as in Caucasians, but at any given total cholesterol or LDL level, South Asian immigrants have a greater CAD risk than Caucasians [36-38]. Therefore, South Asian immigrants with dyslipidemias should be treated as aggressively as if they had a CAD risk equivalent to patients with diabetes or CAD.

Over the past decade, lowering LDL levels has been the major target in cardiovascular protection strategies and clinical trials have clearly established that reductions in LDL are associated with a $30-45 \%$ reduction in clinical events [2428]. However, despite low LDL and normal HDL levels, many patients continue to have cardiac events. One can calculate from the published Framingham data [39] that 44\% of the CAD clinical events occurred in men with HDL levels greater than $40 \mathrm{mg} / \mathrm{dl}$ and $43 \%$ in women with HDL levels greater than $50 \mathrm{mg} / \mathrm{dl}$. Because a significant number of CAD events occur in patients with normal LDL and HDL levels, there has been a continuing search for markers with better 
predictive value. Here we present the review of HDL role in preventing $\mathrm{CAD}$ and theories underlying dysfunctional HDL concepts. In this paper, dysfunctional HDL (Dys-HDL) and pro-inflammatory HDL terms are used inter-changeably

\section{HDL ROLE IN CAD}

HDL is a heterogeneous lipoprotein, containing several surface apolipoproteins (Apo A-I, AII, C, E, AIV, J, and D). Apolipoprotein A-I (Apo A-I) is the principle protein of HDL, which also carries enzymes, such as paraoxonase 1 (PON 1), platelet activating factor (PAF) -acetylhydrolase, lecithin cholesterol acyltransferase (LCAT), and cholesteryl ester transfer protein (CETP). Differences in HDL particle size result mainly from the number of apolipoprotein molecules and the volume of the cholesterol ester in the core of the particle [30].

HDL has antioxidant, anti-inflammatory, and antithrombotic properties that contribute to its function as an anti-atherogenic agent. Although our understanding of how HDL protects against CAD is still incomplete, evidence supports at least three major athero-protective mechanisms of HDL (Table 1).

1. HDL is an integral component of the reverse cholesterol transport process, functioning as a carrier of excess cellular cholesterol from peripheral tissues to the liver, where it is excreted from the body as bile acids and cholesterol. More specifically, HDL mediates efflux of cholesterol from cholesterol-loaded macrophages by passive diffusion, through scavenger receptor B1 (SR B1), and, most significantly, via the protein Apo A-I $[40,41]$. Apo A-I functions through an ATP-binding cassette transporter A1 (ABCA1) in the vessel wall, where it accepts free cholesterol, forming pre-beta HDL that matures after esterification to cholesteryl esters (CE) and then by lecithin-cholesterol acyltransferase to alpha migrating HDL [42].

2. A series of antioxidant enzymes which protect LDL from oxidation are associated with HDL. Oxidized lipids are transferred to HDL from LDL and are hydrolyzed by HDL-associated PON1, LCAT, and platelet activating factor (PAF) acetylhydrolase enzymes [44-49]. The activities of these enzymes destroy oxidized lipids and also inhibit their formation. Removing the oxidized lipids initiates a positive feedback loop that results in further activation of the enzymes and further destruction of the oxidized lipids. In addition, Apo A-I reduces lipid peroxides within LDL, independent of PON1 [45].

3. HDL may protect against CAD by selectively decreasing endothelial cell adhesion molecules, which facilitate the binding of mononuclear cells to the vessel wall and promote lesion development [44, 45, 50].

\section{EVIDENCE THAT HDL MAY NOT BE PROTEC- TIVE: PRO-INFLAMMATORY HDL}

According to several recent studies, in patients with CAD, HDL is not only ineffective as an antioxidant but, paradoxically, appears to be pro-oxidant, promoting LDL oxidation and monocytes chemotactic activity in the human artery wall as well as increase in HDL lipid hydroperoxides, as assessed by its lipid peroxide content [51-55]. In addition, HDL from patients with a history of CAD enhances the oxidation of LDL and of phospholipids in LDL $[51,53]$. This pro-inflammatory HDL, which is dysfunctional, accumulates oxidants that inhibit HDL-associated antioxidant enzymes, render Apo A-I unable to promote ABCA1 mediated cholesterol efflux, and promotes the formation of LDL-derived oxidized lipids [55]; (Figs. 2, 3). The mechanisms underlying this phenomenon are not completely understood. One of the hypothesized mechanisms involves myeloperoxidase [56]. Apo A-I is targeted by myeloperoxidase, and, when oxidized and nitrated, impairs ABCA1-dependent cholesterol efflux [56]. Furthermore, exposing HDL or Apo A-I to myeloperoxidase almost entirely prevents ABCA1-dependent reverse cholesterol transport [55]. It has been hypothesized that a certain variant of Apo A-I is susceptible to oxidation and nitration [57].

Table 1. Pleiotropic Effects of HDL

\begin{tabular}{|c|c|c|}
\hline & HDL & Key References \\
\hline \hline Cell proliferation & $\begin{array}{c}\uparrow \text { proliferation, } \\
\text { lapoptosis }\end{array}$ & {$[41,42]$} \\
\hline Vascular tone & $\begin{array}{c}\uparrow \text { NO, } \\
\uparrow \text { PGI }_{2}\end{array}$ & {$[43,44]$} \\
\hline Inflammation & $\begin{array}{c}\uparrow \text { VCAM- } 1, \uparrow \text { ICAM-1, } \\
\downarrow \text { E-selectin, } \uparrow \text { TGF- } \beta 2\end{array}$ & {$[40,44,45,50]$} \\
\hline $\begin{array}{c}\text { Coagulation, } \\
\text { fibrinolysis }\end{array}$ & $\begin{array}{c}\uparrow \text { TF, } \downarrow \text { PAF, } \uparrow \text { activated } \\
\text { protein C, } \uparrow \text { protein S }\end{array}$ & {$[40]$} \\
\hline LDL oxidation & $\begin{array}{c}\downarrow \text { metal ions } \\
\text { mediated oxidation }\end{array}$ & {$[39,40,4144]$} \\
\hline & $\begin{array}{r}\downarrow 12-\text { Lox } \\
\text { mediated oxidation }\end{array}$ & \\
\hline & $\begin{array}{c}\text { Scavenge of lipid peroxides } \\
\text { and LPC, PON, PAF-AH } \\
\text { and GPX }\end{array}$ & \\
\hline
\end{tabular}

$\mathrm{CETP}=$ Cholesteyl ester transfer protein, $\mathrm{GPX}=$ Glutathione peroxidase, $\mathrm{HL}=$ Hepatic lipase, HPETE $=$ Hydro-peroxy eicosatetraenoic acid, HPODE $=$ Hydroperoxyoctadecadienoic acid, $\mathrm{PON}=$ Paraoxonase, $\mathrm{PAF}-\mathrm{AH}=$ Platelet activation factor acetyl hydrolase, $\mathrm{PS}=$ Phosphatidylserine, $\mathrm{PC}=$ Phosphatidylcholine, $\mathrm{PLTP}=\mathrm{Phospholipid}$ transfer protein, LCAT $=$ Lecithin-choloeterol acyltransferase, SR-BI= Scavenger Receptor type BI, Lox= Lipoxygenase.

The diagnosis of dysfunctional HDL has historically been made with a cell-based assay that requires endothelial cells, smooth muscle cells, and monocytes. However, the use of a cell-based assay is not practical for large-scale studies. Recently, a cell free assay was developed to detect HDL that is dysfunctional in preventing the formation or inactivation of oxidized phospholipids $[58,59]$. This is a rapid test for HDL function that does not require cells and gives results highly comparable to those of the previously described cell-based assay [58]. Using this assay, investigators determined that HDL from patients with documented CAD was proinflammatory, while HDL from normal subjects was antiinflammatory. These patients had normal levels of blood lipids, had no major risk factors for CAD, and therefore, would not have been predicted to be at risk for atherosclerosis by conventional risk factor analysis. In short, the new cell-free assay has the potential to allow wide-spread testing for HDL that is dysfunctional and identification of individuals at risk for CAD. 


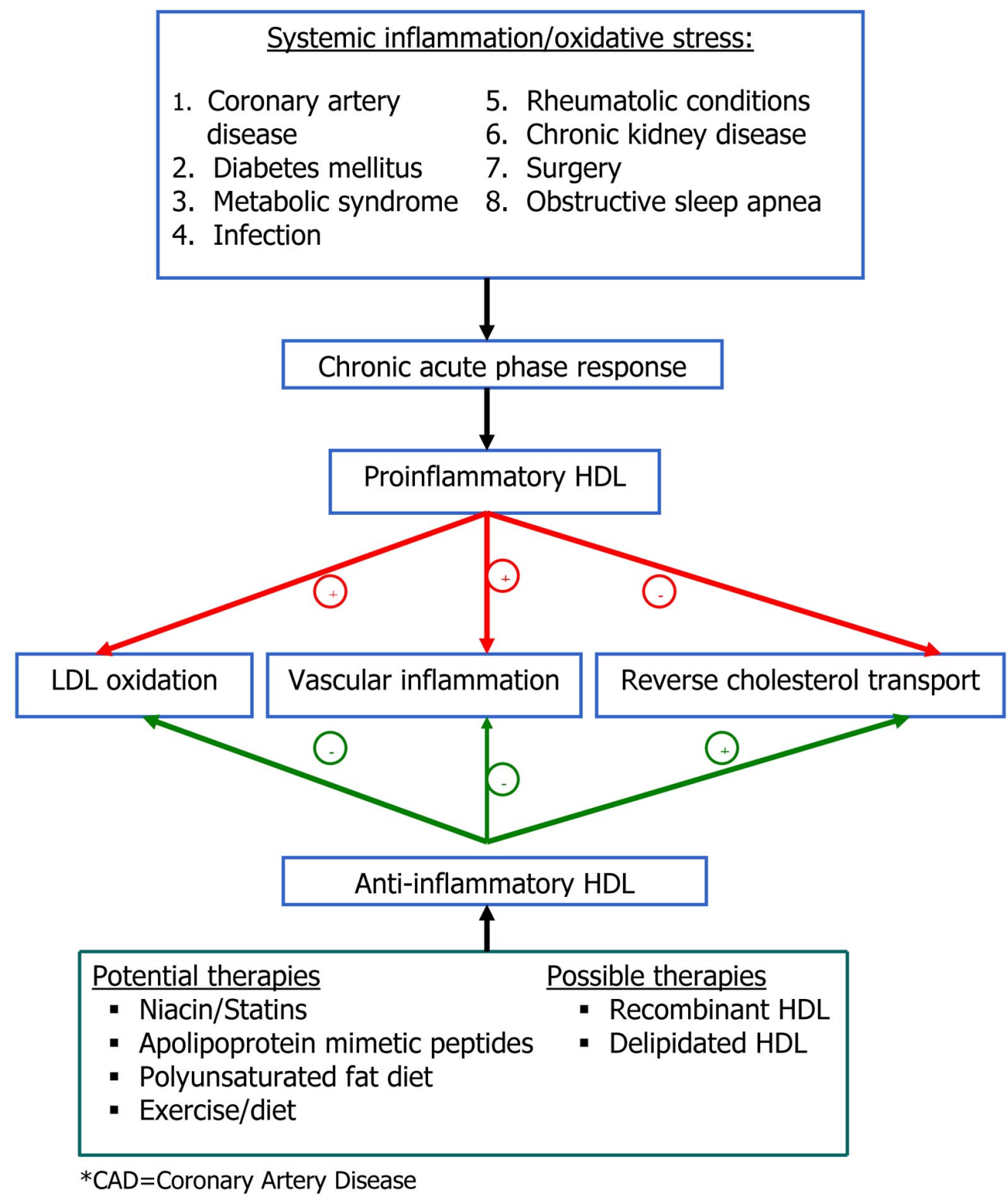

Fig. (2). Dysfunctional HDL and it's adverse effects.

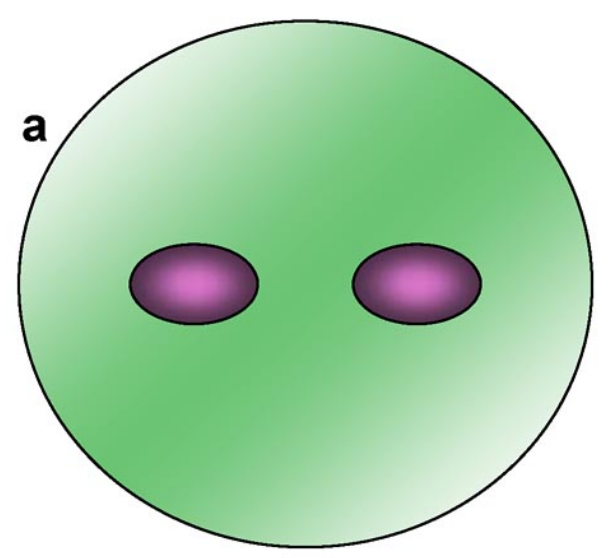

Anti- Inflammatory

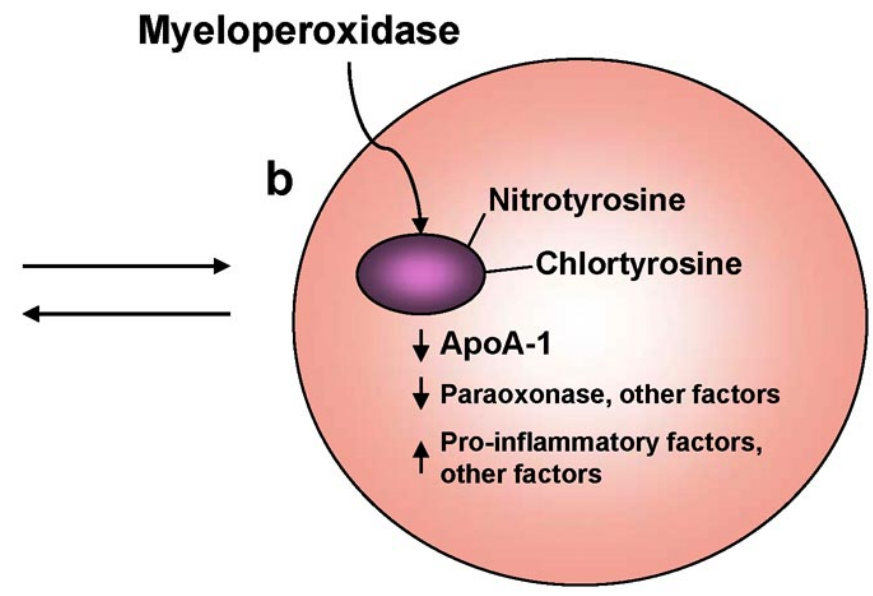

Pro- Inflammatory

Fig. (3). Model of bidirectional conversion of high-density lipoprotein (HDL) from anti-inflammatory (a) to pro-inflammatory (b) Modified from Fogelman et al. Nat Med 2004 Sep; 10(9): 902-3. 
The inflammatory/anti-inflammatory properties of HDL can be determined by calculating HDL inflammatory index $[58,59]$. This index is calculated by normalizing the cell-free assay values obtained for a standard LDL alone to $<1.0$. Using normalization procedure, a test HDL is classified as proinflammatory (dysfunctional) when addition of the test HDL along with an LDL standard to the assay results in a normalized value of 1.0 or greater. Conversely, a value less than 1.0 classifies the test HDL as anti-inflammatory. In recent studies of Caucasians and Chinese Asians with CAD, HDL was not only found to be ineffective as an antioxidant but, paradoxically, appeared to be pro-oxidant $[58,60]$ The Association of Dys-HDL has also been seen in metabolic syndrome, diabetes, systemic lupus erthematosis and other diseases causing systemic infection [61-68]. This pro-inflammatory HDL or Dys-HDL accumulates oxidants that inhibit HDLassociated antioxidant enzymes, render Apolipoprotein A-I (Apo A-I), the main protein component of HDL unable to promote ABCA1 mediated cholesterol efflux (Fig. 3), and promotes the formation of LDL-derived oxidized lipids [58, 59] Association of Dys-HDL with CAD has been seen in small scale studies of Caucasians [58, 59, 69]

\section{PRO-INFLAMMATORY (DYSFUNCTIONAL) HDL IN SOUTH ASIAN IMMIGRANTS?}

The current data indicates that a $1 \%$ increase in HDL serum concentration can decrease cardiovascular risk by 2$3 \%$, independent of LDL levels [30]. However, HDL can have this protective effect only if it is functional. The incidence of pro-oxidant or pro-inflammatory HDL (dysfunctional HDL) in South Asian immigrants is not known.

A small study done on South Asian immigrants without CAD showed inflammatory index values of $\geq 1.00$ in 50 percent $(95 \%$ CI $0.8772,1.4333)$ suggesting proinflammatory HDL $[70,71]$. In addition, pro-inflammatory HDL ( $\geq 1.00$ ) was associated with sub-clinical CAD, using IMT values $\geq 0.80 \mathrm{~mm}$ as surrogate marker for CAD ( $\mathrm{p}=$ 0.04 ) [42]. The mean HDL inflammatory Index was 0.8772 in the group with CAD and 0.6269 in the group without CAD.

Given that animal and small-scale human studies suggest that measures of the quality and functionality of HDL can provide an improved means of identifying subjects at increased risk for atherosclerotic events, compared with the current practice of only measuring the level of HDL [32], the level of dysfunctional HDL and its association with CAD in South Asian immigrants needs to be explored in bigger studies. Given the results of small studies, we can hypothesize that South Asian immigrant populations have a high prevalence of dysfunctional HDL and that this could be related to their excessive risk of CAD. Similarly, South Asian immigrants carry an increased prevalence of metabolic syndrome and diabetes (sub-clinical chronic inflammation) as compared to other groups, therefore, we predict that this population has increased dysfunctional HDL that could be related to coronary events $[16,18,19]$. Patients with metabolic syndrome tend to have dysfunctional HDL (pro-inflammatory HDL) more often than controls [62]. Identification of dysfunctional HDL and its association with CAD and metabolic syndrome in South Asian immigrants will help to identify high risk individuals; high risk that cannot be explained by traditional risk factors. Patients found to have dysfunctional HDL and no other CAD risk factors can be targeted for early lipid lowering treatment which has been shown to improve HDL anti-inflammatory function [59, 60, 69].

\section{APO A-I AND GENE POLYMORPHISMS}

Apo A-I (APOAI gene, Apo A-I protein) is the major protein of HDL and consists of 243 amino acid long peptide, synthesized mainly in the liver and to some extent in the small intestine. The inverse relationship between HDL plasma levels and CAD has been attributed to the role that HDL and its major constituent Apo A-I play in reverse cholesterol transport (RCT). The efficiency of RCT depends on the specific ability of Apo A-I to promote cellular cholesterol efflux, bind lipids, activate lecithin: cholesterol acyltransferase (LCAT), and form mature HDL that interacts with specific receptors and lipid transfer proteins [72-78]. The APOAI gene is present along with the APOC3 and APOA4 genes, on chromosome 11(11q23.3-qter). It has also been shown that the A allele of the APOAI gene contributes to the severity of CAD and low levels of HDL among Northern Indians [75].

Epidemiological studies have shown that HDL and Apo A-I levels are inversely correlated with the risk of developing CAD [57, 67, 68, 72]. Although various factors such as genetic variations, diet, exercise, alcohol, smoking, hormones, and certain drugs can significantly influence the levels of HDL and Apo A-I [76], family and twin studies have demonstrated a strong genetic heritability, accounting for up to $66 \%$ of the variability of HDL and Apo A-I levels [77-79]. Furthermore, $40-60 \%$ of the inter-individual variation in HDL concentrations is controlled at the genetic level $[80,81]$ and the strong positive correlation between plasma levels of Apo A-I and HDL suggests that Apo A-I gene polymorphisms may be linked to variability in HDL levels as well as to dysfunction $[57,67,72]$.

More than 40 mutations in Apo A-I have been identified in several ethnic populations [ 82-88] each producing differing HDL activity and levels. Apo A-I gene mutations are separated into three classes. Class I includes mutations that prevent the formation of Apo A-I; class II defects lead to expression of a truncated Apo A-I protein; and class III defects result in an altered functional state of Apo A-I. Not surprisingly, class I mutations are associated with CAD, xanthomatosis, and corneal opacifications, whereas class II mutations exhibit variable phenotypes [84-88]. Mutations affecting the structure of Apo A-I (nonsense mutations with premature stop codons or large genomic deletions) result in an absence of Apo A-I in plasma and a marked reduction in HDL levels [88]. Interestingly, of the 12 mutations that truncate Apo A-I, not all are associated with CAD. Further, several point mutations have been identified [80-83], and one in particular is associated with low levels of HDL but not with an increased CAD risk and is, instead, associated with a reduction in CAD risk [84]. This Apo A-I mutations is called Apo A-I milano (Apo A-I $\mathrm{I}_{\mathrm{Arg}} 173 \mathrm{Cys}$ ).

\section{APO A-I POLYMORPHISMS IN SOUTH ASIAN IM- MIGRANTS}

A majority of the studies on Apo A-I polymorphisms and their association with HDL level and CAD have been carried 
out in Caucasian and other populations. The association of Apo A-I gene polymorphisms with carotid IMT as a surrogate marker for atherosclerosis has been examined, but not fully. For example, Apo A-I (L178P) was found to be associated with high IMT measurements $(p<0.001)$ in a European population, however due to the small sample size, results can not be generalized [86]. Similarly, Apo A-I/CIII/A-IV SstI polymorphism was found to be associated with high carotid IMT measurements in a study of a young Finnish population [87]. However, the role of Apo A-I polymorphisms in individuals with metabolic syndrome and its association with dysfunctional HDL has not yet been fully studied. A few studies have examined Apo A-I polymorphisms in native populations of South Asians from India, however, to our knowledge, no study has examined Apo A-I polymorphisms in South Asian immigrants and its association with dysfunctional HDL, IMT, or CAD. Polymorphisms in Apo A-I and other lipid metabolism-related genes have been suggested to be clinically useful in assessing an individual's risk for cardiovascular disease and in conducting genetic-epidemiological evaluations [85].

Given that South Asian immigrants are significantly under-represented in major clinical trials, evidence-based management strategies for treatment and prevention of CAD specifically in this population is seriously lacking. A literature search for Apo A-I gene mutations in South Asian populations yielded a small solo study that showed polymorphisms in the Apo lipoprotein C-III promoter gene that were associated with features of metabolic syndrome in South Asian Indians, however, the relationship of these polymorphisms to CAD was not examined [86-89]. A recent small study conducted on Pakistanis suggested that the promoter region of the Apo A-I gene may play a role in determining blood pressure [90]; however, due to insufficient power, these results cannot be generalized. Chhabra and colleagues [91] found a correlation between the expression of the Apo A-I G-75A polymorphism in northern Indians, the severity of CAD, and low levels of HDL; however this study was restricted to one ethnic group and relationship was not examined in other ethnic groups. Studies have shown that South Indians carry more CAD risk as compare to North Indians [35].

In small study on South Asian immigrants, six novel polymorphisms were identified, one of which, G4 (C938T), was significantly associated with low $(<40 \mathrm{mg} / \mathrm{dl}) \mathrm{HDL}$ levels $(p=0.03)$ [92]. Further research is required to explore Apo A-I polymorphisms in South Asian immigrants and correlate possible associations with dysfunctional HDL and CAD. Moreover, the identification of these genes may lead to screening tests that will allow persons at risk for developing $\mathrm{CAD}$ to be identified early enough that prevention/intervention strategies can be implemented to prevent or ameliorate the disease process, and may also lead to the development of gene therapy mechanisms useful in the treatment of CAD in South Asian immigrants.

\section{CONCLUSION}

South Asian immigrants are the second fastest growing Asian immigrant population in the United States, constituting a large, visible minority, and are known to be at heightened risk for premature CAD. Conventional risk factors clearly confer risk in South Asians but do not adequately explain their excess risk compared with other populations. New risk factors and markers like dysfunctional HDL, known genetic polymorphisms though shown to be linked with CAD; however greater research is required in South Asians. The rates of CAD have accelerated dramatically amongst South Asians, driven to an important extent by the atherogenic dyslipidemia and type 2 diabetes that have become so common amongst them. South Asians may have a genetic predisposition to $\mathrm{CAD}$; however, environmental, nutritional, and lifestyle factors may also be responsible. South Asians have a much higher prevalence of metabolic syndrome, diabetes, insulin resistance (and resultant hyperinsulinemia), central obesity, dyslipidemias (lower highdensity lipoprotein, increased lipoprotein[a], higher triglyceride levels), increased thrombotic tendency (increased plasminogen activator inhibitor-1 and decreased tissue plasminogen activator levels), decreased levels of physical activity, and low birth weights. In addition, the dietary indiscretions and sedentary lifestyle practiced by most South Asians puts them at a higher risk. A multidisciplinary approach involving the population at risk, healthcare personnel, and the government is required to diminish the incidence.

The key to combating the increasing incidence of CAD among South Asians is early diagnosis and treatment of CAD risk factors to prevent future CAD morbidity and mortality. An aggressive treatment of known risk factors through both an individual-based as well as a population-based approach aimed at comprehensive risk factor reduction is needed. The Assessment of dysfunctional HDL and its association with coronary artery diseases in a larger South Asian immigrant population is under way. In addition, further research is needed to discover new risk factors like dysfunctional HDL that can be responsible for an excess CAD risk not explained by conventional risk factors.

\section{ACKNOWLEDGEMENTS}

I would like to thank Ms. Cathey Ellis, my Office Specialist for her help in editing and format this manuscript.

\section{AUTHORS' CONTRIBUTIONS}

SD conceived the idea and wrote whole paper including literature search.

\section{REFERENCES}

[1] Nordlie MA, Wold LE, Kloner RA. Genetic contributors toward increased risk for ischemic heart disease. J Mol Cell Cardiol 2005; 39: 667-79.

[2] Uppaluri CR. Heart disease and its related risk factors in Asian Indians. Ethn Dis 2002; 12: 45-53.

[3] Joshi P, Islam S, Pais P, et al. Risk factors for early myocardial infarction in South Asians compared with individuals in other countries. JAMA 2007; 297: 286-94.

[4] Enas EA, Garg A, Davidson MA, Nair VM, Huet BA, Yusuf S Coronary heart disease and its risk factors in first-generation immigrant Asian Indians to the United States of America. Indian Heart J 1996; 48: 343-53.

[5] Enas EA, Mehta J. Malignant coronary artery disease in young Asian Indians: thoughts on pathogenesis, prevention, and treatment. Clin Cardiol 1995; 18: 131-5.

[6] Enas EA, Yusuf S, Mehta J. Prevalence of coronary artery disease in Asian Indians. Am J Cardiol 1992; 70: 945-9.

[7] Mohan V, Deepa R, Shanthi RSS, Premalatha G. Chennai Urban Population Study (CUPS No.5). Prevalence of coronary artery disease and its relationship to lipids in a selected population in South India. The Chennai Urban Population Study (CUPS No. 5). J Am Coll Cardiol 2001; 38: 682-7. 
[8] Goyal A, Yusuf S. The burden of cardiovascular disease in the Indian subcontinent. Indian J Med Res 2006; 124: 235-44.

[9] Klatsky AL, Tekawa I, Armstrong MA, Sidney S. The risk of hospitalization for ischemic heart disease among Asian Americans in northern California. Am J Public Health 1994; 84: 1672-5.

[10] Bhopal R. Epidemic of cardiovascular disease in South Asians. BMJ 2002; 324: 625-6.

[11] Anand SS, Yusuf S, Vuksan V, et al. Differences in risk factors, atherosclerosis, and cardiovascular disease between ethnic groups in Canada: the Study of Health Assessment and Risk in Ethnic groups (SHARE). Lancet 2000; 356: 279-84.

[12] Bhatnagar D, Anand IS, Durrington PN, et al. Coronary risk factors in people from the Indian subcontinent living in West London and their siblings in India. Lancet 1995; 345: 405-9.

[13] Williams B. Westernized Asians and cardiovascular disease: nature or nurture? Lancet 1995; 345: 401-2.

[14] Petersen S, Peto V, Rayner M. Coronary heart disease statistics, British Heart Foundation, London 2004. Available from: URL: (http: //www.heartstats.org/datapage.asp?id=1652)

[15] Bedi US, Singh S, Syed A, Aryafar H, Arora R. Coronary artery disease in South Asians: an emerging risk group. Cardiol Rev 2006; 14: 74-80.

[16] Grundy SM. Obesity, metabolic syndrome, and coronary atherosclerosis. Circulation 2002; 105: 2696-8.

[17] Forouhi N, McKeigue P. How far can risk factors account for excess coronary mortality in South Asians? Can J Cardiol 1997; 13: 47B.

[18] Forouhi NG, Sattar N, Tillin T, McKeigue PM, Chaturvedi N. Do known risk factors explain the higher coronary heart disease mortality in South Asian compared with European men? Prospective follow-up of the Southall and Brent studies. Diabetologia 2006; 49: 2580-8.

[19] Tillin T, Forouhi N, Johnston DG, McKeigue PM, Chaturvedi N, Godsland IF. Metabolic syndrome and coronary heart disease in South Asians, African-Caribbeans and white Europeans: a UK population-based cross-sectional study. Diabetologia 2005; 48: 649-56.

[20] Raji A, Gerhard H, Warren M. Insulin resistance and vascular dysfunction in non diabetic Asian Indians. J Clin Endocrinol Metab 2004; 89: 3965-72.

[21] McGovern PG, Pankow JS, Shahar E, et al. Recent trends in acute coronary heart disease-mortality, morbidity, medical care, and risk factors. The Minnesota Heart Survey Investigators. N Engl J Med 1996; 334: 884-90

[22] Luepker RV, Arnett DK, Jacobs JR, et al. Trends in blood pressure, hypertension control, and stroke mortality: the Minnesota Heart Survey. Am J Med 2006; 119: 42-9.

[23] Kottke TE, Thomas RJ, Lopez-Jimenez F, et al. CardioVision 2020: Program acceptance and progress after 4 years. Am J Prev Med 2006; 30: $137-43$.

[24] Scandinavian Simvastatin Survival Study Group. Randomized trial of cholesterol lowering in 4444 patients with coronary heart disease: the Scandinavian Simvastatin Survival Study (4S). Lancet 1994; 344: 1383-9.

[25] Shepherd J, Cobbe SM, Ford I, et al. West of Scotland Coronary Prevention Study Group. Prevention of coronary heart disease with pravastatin in men with hypercholesterolemia. N Engl J Med 1995; 333: 1350-1.

[26] Sacks FM, Pfeffer MA, Moye LA, et al. The effect of pravastatin on coronary events after myocardial infarction in patients with average cholesterol levels. N Engl J Med 1996; 335: 1001-9.

[27] Downs JR, Clearfield M, Weis S, et al. Primary prevention of acute coronary events with lovastatin in men and women with average cholesterol levels: results of AFCAPS/TexCAPS. Air Force/Texas Coronary Atherosclerosis Prevention Study. JAMA 1998; 279: 1615-22.

[28] Heart Protection Study Collaborative Group. MRC/BHF Heart Protection Study of cholesterol lowering with Simvastatin in 20, 536 high-risk individuals: a randomized placebo-controlled trial. Lancet 2002; 360: 7-22.

[29] Enas EA. Coronary artery disease epidemic in Indians: a cause for alarm and call for action. J Indian Med Assoc 2000, 98: 694-5, 697702 .

[30] Gordon DJ, Probstfield JL, Garrison RJ, et al. High-density lipoprotein cholesterol and cardiovascular disease. Four prospective American studies. Circulation 1989; 79: 8-15.

[31] Tulenko TN, Sumner AE. The physiology of lipoproteins. J Nucl Cardiol 2002; 9: 638-49.

[32] Executive summary of the third report of the National Cholesterol Education Program (NCEP) Expert Panel on Detection, Evaluation, and Treatment of High Blood Cholesterol in Adults (Adult Treatment Panel III). Expert Panel on Detection, Evaluation, and Treatment of High Blood Cholesterol in Adults. JAMA 2001; 285: 2486-97.

[33] Anand SS, Yusuf S, Vuksan V, et al. Differences in risk factors, atherosclerosis, and cardiovascular disease between ethnic groups in Canada: the Study of Health Assessment and Risk in Ethnic groups (SHARE). Lancet 2000; 356: 279-84.

[34] Kalhan R, Puthawala K, Agarwal S, Amini SB, Kalhan SC. Altered lipid profile, leptin, insulin, and anthropometry in offspring of South Asian immigrants in the United States. Metabolism 2001; 50: 1197 202.

[35] Hoogeveen RC, Gambhir JK, Gambhir DS, et al. Evaluation of Lp[a] and other independent risk factors for CHD in Asian Indians and their USA counterparts. J Lipid Res 2001; 42: 631-8.

[36] Forouhi NG, Sattar N. CVD risk factors and ethnicity--a homogeneous relationship? Atheroscler 2006; 7: 11-9.

[37] D'Agostino RB Sr, Grundy S, Sullivan LM, Wilson P, CHD Risk Prediction Group. Validation of the Framingham coronary heart disease prediction scores: results of a multiple ethnic groups investigation. JAMA 2001; 286: 180-7.

[38] Bhopal R, Fischbacher C, Vartiainen E. Predicted and observed cardiovascular disease in South Asians: application of FINRISK, Framingham and SCORE models to Newcastle Heart Project data. J Public Health 2005; 27: 93-100.

[39] Castelli WP, Garrison RJ, Wilson PW, Abbott RD, Kalousdian S, Kannel WB. Incidence of coronary heart disease and lipoprotein cholesterol levels: The Framingham Study. J Am Med Assoc 1986; 256: 2835-8.

[40] Yancey PG, Bortnick AE, Kellner-Weibel G, de la Llera-Moya M, Phillips MC, Rothblat GH. Importance of different pathways of cellular cholesterol efflux. Arterioscler Thromb Vasc Biol 2003; 23: 7129.

[41] Navab M, Berliner JA, Subbanagounder G, et al. HDL and the inflammatory response induced by LDL-derived oxidized phospholipids. Arterioscler Thromb Vasc Biol 2001; 21: 880.

[42] Dodani S, Kaur R, Reed GL, George V, Sharma G, Marion L. The association of carotid Intima media thickness with dysfunctional HDL in South Asians. Arch Med Sci 2008; 4: 40-6.

[43] Navab M, Hama SY, Anantharamaiah GM, et al. Normal high density lipoprotein inhibits three steps in the formation of mildly oxidized low density lipoprotein: steps 2 and 3. J Lipid Res 2000; 41: 1495; Williams DL, Connelly MA, Temel RE, et al. Scavenger receptor B1 and cholesterol trafficking. Curr Opin Lipidol 1999, 10: 329-39.

[44] Barter PJ, Baker PW, Rye KA. Effect of high-density lipoproteins on the expression of adhesion molecules in endothelial cells. Curr Opin Lipidol 2002; 13: 285-8.

[45] Calabresi L, Gomaraschi M, Franceschini G. Endothelial protection by high-density lipoproteins: from bench to bedside. Arterioscler Thromb Vasc Biol 2003; 23: 1724-31.

[46] Yuhanna IS, Zhu Y, Cox BE, et al. High-density lipoprotein binding to scavenger receptor-BI activates endothelial nitric oxide synthase. Nat Med 2001; 7: 853-7.

[47] Norata GD, Callegari E, Marchesi M, Chiesa G, Eriksson P, Catapano AL. High-density lipoproteins induce transforming growth factor-beta2 expression in endothelial cells. Circulation 2005; 111 : 2805-11

[48] Takahashi Y, Smith JD. Cholesterol efflux to apolipoprotein AI involves endocytosis and resecretion in a calcium-dependent pathway. Proc Natl Acad Sci USA 1999, 96: 11358-63.

[49] Navab M, Hama SY, Anantharamaiah GM, et al. Normal high density lipoprotein inhibits three steps in the formation of mildly oxidized low density lipoprotein: steps 2 and 3. J Lipid Res 2000; 41: 1495-508.

[50] Barter PJ, Baker PW, Rye KA. Effect of high-density lipoproteins on the expression of adhesion molecules in endothelial cells. Curr Opin Lipidol 2002; 13: 285-8.

[51] Navab M, Anantharamaiah GM, Reddy ST, Van Lenten BJ, Ansell BJ, Fogelman AM. Mechanisms of disease: proatherogenic HDL--an evolving field. Nat Clin Pract Endocrinol Metab 2006; 2: 504-11.

[52] Ansell BJ, Fonarow GC, Fogelman AM. High-density lipoprotein: is it always atheroprotective? Curr Atheroscler Rep 2006; 8: 405-11. Ansell BJ, Fonarow GC, Fogelman AM. High-density lipoprotein function recent advances. J Am Coll Cardiol 2005; 46: 1792-8.

[54] Navab M, Ananthramaiah GM, Reddy ST, et al. The double jeopardy of HDL. Ann Med 2005; 37: 173-8. 
[55] Fogelman AM. When good cholesterol goes bad. Nat Med 2004; 10 : 902-3.

[56] Zheng L, Nukuna B, Brennan ML, et al. Apolipoprotein A-I is a selective target for myeloperoxidase-catalyzed oxidation and functional impairment in subjects with cardiovascular disease. J Clin Invest 2004; 114: 529-41.

[57] Navab M, Anantharamaiah GM, Reddy ST, et al. Human apolipoprotein A-I and A-I mimetic peptides: potential for atherosclerosis reversal. Curr Opin Lipidol 2004; 15: 645-9.

[58] Navab M, Hama SY, Hough GP, Subbanagounder G, Reddy ST, Fogelman AM. A cell-free assay for detecting HDL that is dysfunctional in preventing the formation of or inactivating oxidized phospholipids. J Lipid Res 2001; 42: 1308-17.

[59] Ansell BJ, Navab N, Hama S. Inflammatory/anti-inflammatory properties of high-density lipoprotein distinguish patients from control subjects better than high-density lipoprotein cholesterol levels and are favorably affected by Simvastatin treatment. Circulation 2003; 108: 2751-6.

[60] Sun Y, Yang Y, Pei W, Wu Y, Zhao J. Is elevated high-density lipoprotein cholesterol always good for coronary heart disease? Clin Cardiol 2007; 30: 576-80.

[61] de Souza JA, Vindis C, Hansel B, et al. Metabolic syndrome features small, apolipoprotein A-I-poor, triglyceride-rich HDL3 particles with defective anti-apoptotic activity. Atherosclerosis 2008; 197: 84-94.

[62] Hansel B, Giral P, Nobecourt E, et al. Metabolic syndrome is associated with elevated oxidative stress and dysfunctional dense highdensity lipoprotein particles displaying impaired antioxidative activity. J Clin Endocrinol Metab 2004; 89: 4963-71.

[63] Nicholls SJ, Lundman P, Harmer JA, et al. Consumption of saturated fat impairs the anti-inflammatory properties of high-density lipoproteins and endothelial function. J Am Coll Cardiol 2006; 48: 715-20.

[64] Kaysen GA. Disorders in high-density metabolism with insulin resistance and chronic kidney disease. J Ren Nutr 2007; 17: 4-8.

[65] Tan KC, Chow WS, Lam JC, et al. HDL dysfunction in obstructive sleep apnea. Atherosclerosis 2006; 184: 377-82.

[66] Van Lenten BJ, Hama SY, de Beer FC, et al. Anti-inflammatory HDL becomes pro-inflammatory during the acute phase response. Loss of protective effect of HDL against LDL oxidation in aortic wall cell co-cultures. J Clin Invest 1995; 96: 2758-67.

[67] McMahon M, Grossman J, FitzGerald J, et al. Proinflammatory highdensity lipoprotein as a biomarker for atherosclerosis in patients with systemic lupus erythematosus and rheumatoid arthritis. Arthritis Rheum 2006; 54: 2541-9.

[68] Gowri MS, Van der Westhuyzen DR, Bridges SR, Anderson JW. Decreased protection by HDL from poorly controlled type 2 diabetic subjects against LDL oxidation may be due to the abnormal composition of HDL. Arterioscler Thromb Vasc Biol 1999; 19: 2226-33.

[69] Ansell BJ, Fonarow GC, Navab M, Fogelman AM. Modifying the anti-inflammatory effects of high-density lipoprotein. Curr Atheroscler Rep 2007; 9: 57-63.

[70] Dodani S, Kaur R, Mohammad N, et al. Can dysfunctional HDL explain excess risk of coronary artery diseases in south Asian immigrants? Int J Cardiol 2008; 129(1): 125-32.

[71] Dodani S, Kaur R, Reed GL, George V, Sharma G, Marion L. The association of carotid Intima media thickness with dysfunctional HDL in South Asians. Arch Med Sci 2008; 4(1): 40-6.

[72] Stampfer MJ, Sacks FM, Salvini S, Willett WC, Hennekens CH. A prospective study of cholesterol, apolipoproteins, and the risk of myocardial infarction. N Engl J Med 1991; 325: 373-81.

[73] Frank PG, Yves LM. Apolipoprotein A-I: structure-function relationships. J Lipid Res 2000; 41: 853-72.

[74] Karathanasis SK. Apolipoprotein multigene family: tandem organization of human apolipoprotein AI, CIII, and AIV genes. Proc Natl Acad Sci USA 1985; 82: 6374-8.
[75] Chhabra S, Narang R, Lakshmy R, Das N. APO A!-75 G to A substitution associated with severe forms of CAD, lower levels of HDL and Apo A-1 among Northern Indians. Dis Markers 2005; 21: 169-74.

[76] Jadhav UM, Kadam NN. Apolipoproteins: correlation with carotid intima media thickness and coronary artery disease. J Assoc Physicians India 2004; 52:370-5.

[77] Lusis AJ, Fogelman AM, Fonarow GC. Genetic basis of atherosclerosis: part II: clinical implications. Circulation 2004; 110: 2066-71.

[78] Frank PG, Marcel YL. Apolipoprotein A-I: structure; -function relationships. J Lipid Res 2000; 41: 853-72.

[79] Calabresi L, Franceschini G. High density lipoprotein and coronary heart disease: Insights from mutations leading to low high density lipoprotein. Curr Opin Lipidol 1997; 8: 219-24.

[80] Koistinen MJ, Huikuri HV, Korhonen UR, et al. Asymptomatic coronary artery disease in diabetes: relation to common risk factors, lipoproteins, apolipoproteins and apo E polymorphism. Acta Diabetol 1994; 31:210-4.

[81] Moll PP, Michel VV, Weidman WH, Kottke BA. Genetic determination of plasma apolipoprotein A-I in a population based sample. Am J Hum Genet 1989; 44: 24-39.

[82] Boekholdt SM, Souverein OW, Tanck MW, et al. Common variants of multiple genes that control reverse cholesterol transport together explain only a minor part of the variation of HDL cholesterol levels. Clin Genet 2006; 69: 263-70

[83] Pulkkinen A, Viitanen L, Kareinen A, Lehto S, Laakso M. MspI polymorphism at $+83 \mathrm{bp}$ in intron 1 of the human apolipoprotein $\mathrm{A} 1$ gene is associated with elevated levels of HDL cholesterol and apolipoprotein A1 in nondiabetic subjects but not in type 2 diabetic patients with coronary heart disease. Diabetes Care 2000; 23: 791-5.

[84] Wang XL, Liu SX, McCredie RM, Wilcken DL. Polymorphisms at the 5 prime-End of the Apolipoprotein AI Gene and Severity of Coronary Artery Disease. J Clin Invest 1996; 98: 372-7.

[85] Perez-Mendez O, Bruckert E, Franceschini G, et al. Metabolism of apolipoproteins AI and AII in subjects carrying similar apoAI mutations, apoAI Milano and apoAI Paris. Atherosclerosis 2000; 148: 317.

[86] Hovingh GK, Brownlie A, Bisoendial RJ, et al. A novel apoA-I mutation (L178P) leads to endothelial dysfunction, increased arterial wall thickness, and premature coronary artery disease. J Am Coll Cardiol 2004, 44: 1429-35.

[87] Islam MS, Raitakari OT, Juonala M, et al. Apolipoprotein A-I/C III/A-IV SstI and apolipoprotein B XbaI polymorphisms and their association with carotid artery intima-media thickness in the Finnish population. The Cardiovascular Risk in Young Finnish Study. Atherosclerosis 2005, 180: 79-86.

[88] Kobayashi KY, Yanagi H, Fukayama H, et al. Frequent occurrence of hypoalphalipoproteinemia due to mutant apolipoprotein A-I gene in the population: a population-based survey. Hum Mol Genet 1998; 8:331-6.

[89] Guettier JM, Georgopoulos A, Tsai MY, et al. Polymorphisms in the fatty acid-binding protein 2 and apolipoprotein C-III genes are associated with the metabolic syndrome and dyslipidemia in a South Indian population. J Clin Endocrinol Metab 2005; 90: 1705-11.

[90] Sadaf A, Siddiqui S, Lestringant GG, Frossard PM. Apolipoprotein AI promoter variant in blood pressure determination. Clin Genet 2002; 61: 314-6.

[91] Chhabra S, Narang R, Lakshmy R, Das N. APOA1-75 G to A substitution associated with severe forms of CAD, lower levels of HDL and apoA-I among Northern Indians. Dis Markers 2005, 21: 169-74.

[92] Dodani S, Dong YB, Zhu H. Can novel ApoAI polymorphism be responsible for low HDL in South Asian Immigrants. Ind J Hum Genet 2008; 14(1): 9-16.

This is an open access article licensed under the terms of the Creative Commons Attribution Non-Commercial License (http://creativecommons.org/licenses/bync/3.0/) which permits unrestricted, non-commercial use, distribution and reproduction in any medium, provided the work is properly cited. 